\title{
Macular pigment optical density in aging eye
}

\author{
Sibel Demirel • Serdar Bilici • Figen Batıglu • \\ Emin Ozmert
}

Received: 21 August 2013 / Accepted: 26 August 2013 / Published online: 20 September 2013

(C) Springer-Verlag Berlin Heidelberg 2013

\section{Dear Editor,}

We would like to thank Dr. Miao et al. for their interest in our recent article discussing the effect of age and cataract surgery on macular pigment optical density (MPOD) [1].

The author claimed that the lack of axial length (AL) measurement was a limiting factor for the current study. To our knowledge, there have been two publications interested in this issue $[2,3]$ and the results were controversial. Neelam et al. revealed that AL was associated with a subject's age, height, and gender. The authors also observed a positive correlation between AL and MPOD; however this relationship ceased to exist after adjusting for age, gender, and height [2]. On the other hand, Tong et al. revealed that MPOD was inversely correlated with axial length. However, in their study, they did not make any adjustment for the factors that effect either MPOD or AL [3]. Therefore we do not think that the lack of AL is a real confounding factor for our study.

Finally, they claimed that our study was not superior to the ones that are already available in the literature that mentioned the relationship between age and MPOD. In the current study, the impact of age on MPOD values was analyzed in healthy individuals which have similar characteristics in terms of factors such as smoking, cataract surgery, color of the iris, and micronutrition supplementation. Also, our study was planned to reveal the relationship between not only age and MPOD but also pseudophakia, especially its duration and
MPOD. Our study has demonstrated that a significant correlation does not exist between age of the patients and MPOD values. MPOD values were lower than age-matched patients who had undergone cataract surgery, and finally, an inverse correlation existed between the duration of the postoperative period after cataract surgery and the MPOD values.

In conclusion, although having some limitations such as its cross-sectional design and lack of information about participants' dietary carotenoid intake, our study differs from alternative ones in the literature by its homogenous subgroups. We agree that larger-scale prospective randomized studies with longer follow-up periods are needed to obtain more enlightened outcomes on this subject.

\section{References}

1. Demirel S, Bilici S, Batioglu F, Ozmert E (2013) The effect of age and cataract surgery on macular pigment optic density: a cross-sectional, comparative study. Graefes Arch Clin Exp Ophthalmol. doi:10.1007/ s00417-013-2424-2

2. Neelam K, Nolan J, Loane E, Stack J, O’Donovan O, Au Eong KG, Beatty S (2006) Macular pigment and ocular biometry. Vision Res 46: 2149-2156

3. Tong N, Zhang W, Zhang Z, Gong Y, Wooten B, Wu X (2013) Inverse relationship between macular pigment optical density and axial length in Chinese subjects with myopia. Graefes Arch Clin Exp Ophthalmol 251:1495-1500

S. Demirel $(\bowtie) \cdot$ S. Bilici $\cdot$ F. Batıglu $\cdot$ E. Ozmert 